\title{
The Cardioprotective Effects of Citric Acid and L-Malic Acid on Myocardial Ischemia/Reperfusion Injury
}

\author{
Xilan Tang, ${ }^{1,2,3}$ Jianxun Liu, ${ }^{1}$ Wei Dong, ${ }^{2,3}$ Peng Li, ${ }^{1}$ Lei Li, ${ }^{1}$ Chengren Lin, \\ Yongqiu Zheng, ${ }^{1}$ Jincai Hou, ${ }^{1}$ and Dan Li ${ }^{1}$ \\ ${ }^{1}$ Experimental Research Center, Xiyuan Hospital, China Academy of Chinese Medical Sciences, Beijing 100091, China \\ ${ }^{2}$ Key Laboratory of Modern Preparation of TCM, Jiangxi University of Traditional Chinese Medicine, Nanchang 330004, China \\ ${ }^{3}$ Beijing University of Chinese Medicine, Beijing 100029, China \\ Correspondence should be addressed to Jianxun Liu; liujx0324@sina.com
}

Received 26 December 2012; Revised 3 April 2013; Accepted 4 April 2013

Academic Editor: Hao Xu

Copyright (C) 2013 Xilan Tang et al. This is an open access article distributed under the Creative Commons Attribution License, which permits unrestricted use, distribution, and reproduction in any medium, provided the original work is properly cited.

\begin{abstract}
Organic acids in Chinese herbs, the long-neglected components, have been reported to possess antioxidant, anti-inflammatory, and antiplatelet aggregation activities; thus they may have potentially protective effect on ischemic heart disease. Therefore, this study aims to investigate the protective effects of two organic acids, that is, citric acid and L-malic acid, which are the main components of Fructus Choerospondiatis, on myocardial ischemia/reperfusion injury and the underlying mechanisms. In in vivo rat model of myocardial ischemia/reperfusion injury, we found that treatments with citric acid and L-malic acid significantly reduced myocardial infarct size, serum levels of TNF- $\alpha$, and platelet aggregation. In vitro experiments revealed that both citric acid and L-malic acid significantly reduced LDH release, decreased apoptotic rate, downregulated the expression of cleaved caspase-3, and upregulated the expression of phosphorylated Akt in primary neonatal rat cardiomyocytes subjected to hypoxia/reoxygenation injury. These results suggest that both citric acid and L-malic acid have protective effects on myocardial ischemia/reperfusion injury; the underlying mechanism may be related to their anti-inflammatory, antiplatelet aggregation and direct cardiomyocyte protective effects. These results also demonstrate that organic acids, besides flavonoids, may also be the major active ingredient of Fructus Choerospondiatis responsible for its cardioprotective effects and should be attached great importance in the therapy of ischemic heart disease.
\end{abstract}

\section{Introduction}

Ischemic heart disease is a leading cause of mortality of the clinical cardiovascular diseases and remains a major public health threat worldwide. Myocardial damage in ischemic heart disease is likely due to ischemia/reperfusion injury. Myocardial ischemia/reperfusion can lead to cardiomyocyte loss by several pathological mechanisms, which contain free radical formation, inflammatory response and endothelial dysfunction, platelet aggregation and microembolization, necrosis and apoptosis, and so forth [1]. Therefore, a pharmacologic approach to ischemia/reperfusion injury remains a longstanding challenge in medicine.

Fructus Choerospondiatis, a widely known Mongolian herb derived from the dried mature fruit of Choerospondias axillaris (Roxb.) Burtt et Hill, with efficacy of "activating vital energy and blood circulation" and "nourishing heart for tranquilization" [2], according to traditional Chinese medicine theory, has been used extensively as a remedy for ischemic heart disease and achieved good clinical efficacy. It consists of several ingredients, including organic acids, phenolic acids, and flavonoids. Previous studies have been focused on flavonoids, which were always considered to be the main active constituents responsible for the pharmacological actions of Fructus Choerospondiatis [3]. However, recent pharmaceutical chemistry studies showed that the content of total flavonoids (mainly quercetin) in Fructus Choerospondiatis was very low and only accounted for $0.0003 \%$ of its water-soluble extracts [4], whereas the content of total organic acids was in significant amounts, up to $8.13 \%$. And citric acid and L-malic acid are two main organic acids of Fructus Choerospondiatis, the content of which accounted for $26.36 \%$ and $22.95 \%$ of total organic acids, respectively [5]. 
Organic acids, which are also widely distributed in fresh fruits, vegetables, and spices besides Chinese herbs, were always considered to be weak in activity and were usually discarded in the extraction process. Therefore, they have been long neglected and their pharmacological actions have not been sufficiently studied. Recent research indicated that some organic acids have various pharmacological effects, including anti-inflammatory response [6,7], antiplatelet aggregation $[8]$, antioxidant $[9,10]$, and reducing cell apoptosis and so on. Therefore, we hypothesized that organic acids might have protective effect on myocardial ischemia/reperfusion injury.

In the present study, we investigated the protective effects of citric acid and L-malic acid on myocardial ischemia/ reperfusion and its possible mechanisms. To the best of our knowledge, the finding that citric acid and L-malic acid have protective effects on myocardial ischemia/reperfusion injury by anti-inflammatory, antiplatelet aggregation, and direct cardiomyocyte protective effects is therefore particularly significant for providing important insights into the understanding of cardioprotective effects of organic acids in traditional Chinese medicine.

\section{Materials and Methods}

2.1. Animals. Male adult Wistar rats (210-240 g body weight) were provided by the Experimental Animal Research Institute, Chinese Academy of Medical Sciences (clean degree, certificate no. SCXK (Jing) 2009-0007). Neonatal SpragueDawley rats (SPF degree, 1 to 2 days old) were purchased from Beijing Vital River Laboratory Animal Technology Co.Ltd., China (certificate no. SCXK (Jing) 2012-0001). Rats were housed under standard conditions and supplied with drinking water and food ad libitum. All animal experiments in this study were performed in accordance with China Academy of Chinese Medical Sciences Guide for Laboratory Animals that conforms to the Guide for the Care and Use of Laboratory Animals published by the U.S. National Institutes of Health (NIH Publications no. 85-23, revised 1996).

2.2. Reagents and Chemicals. Lactate dehydrogenase (LDH) assay kit was purchased from Beijing Zhongsheng Biological Technology Co., Ltd. (batch no. 110391). Rat tumor necrosis factor- $\alpha$ (TNF- $\alpha$ ) Quantikine ELISA kit was obtained from R\&D (Catalog no. RTA00, USA). FITC-annexin $\mathrm{V} /$ propidium iodide apoptosis detection kit was from BD Biosciences (Catalog no. 556547, USA). Nitroblue tetrazolium (N-BT) (Ultra Pure Grade, 0329) and anti-cleaved caspase3 antibody (Catalog no. C8487) were products of Sigma Chemical Co. (USA). The antibodies for anti-p-Akt (Ser473, no. 4060) and anti-Akt (no. 9272) were from Cell Signaling (USA). Citric acid (batch no. 111679-200401) and L-malic acid (batch no. 190014-201001) were purchased from National Institutes for Food and Drug Control (Beijing, China). All chemicals used were of analytical grade.

2.3. Drug Pretreatment and Myocardial Ischemia/Reperfusion Protocols. The studies of citric acid and L-malic acid on myocardial ischemia/reperfusion were performed independently although the experimental designs of them were identical. All animals were randomly assigned to six groups ( $n=10$ for each group). Vehicle or drugs were fed once daily $(10 \mathrm{~mL} / \mathrm{kg})$ for 3 consecutive days prior to the experiment and treated as follows.

Group 1: sham group. Rats were orally administered $0.9 \%$ saline.

Group 2: ischemia/reperfusion (I/R) model control group. Rats were also orally administered $0.9 \%$ saline.

Group 3: diltiazem (Tanabe Seiyaku Co., Ltd., Tianjin)-pretreated group as positive control. Rats were orally administered diltiazem at a dose of $16 \mathrm{mg} / \mathrm{kg}$.

Group 4: clopidogrel (Sanofi Winthrop Industrie)pretreated group as another positive control. Rats were orally administered clopidogrel at a dose of $13.5 \mathrm{mg} / \mathrm{kg}$.

Group 5: citric acid- or L-malic acid-pretreated group. Rats were orally administered citric acid or L-malic acid at a dose of $500 \mathrm{mg} / \mathrm{kg}$.

Group 6: citric acid- or L-malic acid-pretreated group. Rats were orally administered citric acid or L-malic acid at a dose of $250 \mathrm{mg} / \mathrm{kg}$.

Myocardial ischemia/reperfusion injury rat model was constructed by LAD ligation for $40 \mathrm{~min}$ followed by $2 \mathrm{~h}$ reperfusion at $1 \mathrm{~h}$ after the last drug treatment as previously described [11]. Rats were anesthetized with 3.5\% chloral hydrate (Sinopharm Chemical Reagent Co., Ltd., China) (350 mg/kg, i.p.). The neck was opened with a ventral midline incision. The trachea was exposed and cannulated to establish artificial respiration provided by a rodent ventilator (ALCV8S, China) with oxygen at a breath ratio of $1: 2$ and at a frequency of 70 breaths/min with tidal volume of $9.0 \mathrm{~mL}$. Myocardial ischemia was produced by exteriorizing the heart through a left thoracic incision and placing a 5-0 silk suture and making a plastic tubing at the distal $1 / 3$ of the left anterior descending coronary artery. After $40 \mathrm{~min}$ of ischemia, the plastic tubing was cut and the myocardium was reperfused for $2 \mathrm{~h}$.

2.4. Measurement of Myocardial Infarct Size. Myocardial infarct size was evaluated by N-BT staining as previously described [12]. Briefly, at the end of $2 \mathrm{~h}$ reperfusion, rats were anesthetized with $3.5 \%$ chloral hydrate and then sacrificed. The hearts were quickly excised and sliced into 5 sections from the position under the ligation line. The slices were weighed and then immediately incubated in N-BT staining solution dissolved in saline at $25^{\circ} \mathrm{C}$ for $15 \mathrm{~min}$. The infracted size, noninfracted size, and total heart size were measured by multimedia color pathological image analytical system (MPIAS-500, Beijing). The infarction percentage of the ventricle, infarction percentage of the heart, infarction area, and infarction weight were calculated.

2.5. Determination of Inflammatory Cytokine Activity and Platelet Maximum Aggregation Rate. The serum levels of TNF- $\alpha$ were measured using ELISA kits according to the manufacturer's instructions. The absorbance at $450 \mathrm{~nm}$ was 
measured on a microplate reader (BioTek SYNERGY 4, USA).

Blood was collected from the abdominal aorta and anticoagulated with citrate $(3.8 \%, 1: 9, \mathrm{v} / \mathrm{v})$. Platelet-rich plasma (PRP) was obtained by centrifugation at $1000 \mathrm{rpm}$ at $25^{\circ} \mathrm{C}$ for $10 \mathrm{~min}$ and the remaining blood was further centrifuged at $3000 \mathrm{rpm}$ at $25^{\circ} \mathrm{C}$ for $10 \mathrm{~min}$ to prepare platelet-poor plasma (PPP). The platelet concentration was adjusted to $4 \times 10^{8}$ platelets $/ \mathrm{mL}$. The platelet agonist adenosine diphosphate disodium (Shanghai Institute of Biochemistry, Chinese Academy of Sciences) $(1 \mathrm{mmol} / \mathrm{L}, 10 \mu \mathrm{L})$ was used to stimulate platelet aggregation. The level of platelet aggregation was measured using an aggregometer (BS634, Beijing) according to the method reported by Born and Cross [13].

2.6. Cell Culture, Hypoxia/Reoxygenation (H/R), and Drug Treatment. Primary cultures of neonatal rat cardiomyocytes were prepared as previously described with some modifications $[14,15]$. In brief, the hearts were removed and washed with cold PBS. The atria and aorta were discarded. The ventricles were minced with scissors into $1 \mathrm{~mm}^{3}$ fragments. The tissue fragments were digested by gentle shaking at $37^{\circ} \mathrm{C}$ in PBS containing $0.625 \mathrm{~g} / \mathrm{L}$ trypsin (Gibco) and $0.5 \mathrm{~g} / \mathrm{L}$ collagenase II (Gibco). The digestion was conducted for 5-8 times, 10 min each. The dispersed cells were incubated on a $100 \mathrm{~mm}$ culture dish for $1 \mathrm{~h}$ at $37^{\circ} \mathrm{C}$ in a humidified incubator with $5 \% \mathrm{CO}_{2}$. The nonadherent cells were harvested and then seeded into gelatin-coated 6-well plates and incubated in Dulbecco's modified Eagle's medium (DMEM) (Gibco) with $10 \%$ newborn calf serum (TBD21HY, Tianjin), penicillin $(100 \mathrm{U} / \mathrm{mL})$, streptomycin $(100 \mathrm{U} / \mathrm{mL})$, and 5-bromo-2' deoxyuridine $(0.1 \mathrm{mmol} / \mathrm{L}$, sigma), which was used to inhibit cardiac fibroblasts growth.

Hypoxia/reoxygenation-induced cardiomyocytes injury was performed as described previously [15]. Before hypoxia, cardiomyocytes were washed three times with glucosefree Tyrode's solution (in mmol/L: $\mathrm{NaCl} 136.9, \mathrm{KCl} 2.68$, $\mathrm{NaH}_{2} \mathrm{PO}_{4}$ 0.42, $\mathrm{NaHCO}_{3} 11.9, \mathrm{MgCl}_{2} 1.05$, and $\mathrm{CaCl}_{2} 1.8$ ). Cells were incubated with glucose-free Tyrode's solution $\left(2 \mathrm{~mL} /\right.$ well) saturated with $95 \% \mathrm{~N}_{2}$ and $5 \% \mathrm{CO}_{2}$ for $15 \mathrm{~min}$. Cells were placed into a hypoxia chamber which was then ventilated with $95 \% \mathrm{~N}_{2}$ and $5 \% \mathrm{CO}_{2}$ for 15 min and maintained at $37^{\circ} \mathrm{C}$ in a humidified incubator with $5 \% \mathrm{CO}_{2}$ for $3 \mathrm{~h}$. Reoxygenation was accomplished by replacing the glucose-free Tyrode's solution with normal cell medium under normoxic conditions. Reoxygenation time varied depending on the experimental objectives: $2 \mathrm{~h}$ reoxygenation was performed for measurement of $\mathrm{LDH}$ release, whereas $6 \mathrm{~h}$ reoxygenation was performed for flow cytometry assay and measurements of cleaved caspase-3, Akt, and p-Akt expressions.

In the normal control group, cells were cultured with Tyrode's solution that contained $5.5 \mathrm{mmol} / \mathrm{L}$ glucose for $3 \mathrm{~h}$ and reoxygenated with DMEM for $2 \mathrm{~h}$ or $6 \mathrm{~h}$. In the treatment groups, diltiazem (positive control, final concentration: $45 \mu \mathrm{g} / \mathrm{mL}$ ), citric acid, and L-malic acid (final concentrations: $200,100,50,25 \mu \mathrm{g} / \mathrm{mL}$ ) were dissolved with dimethylsulfoxide (DMSO) and added, respectively, into the medium with the ratio of 1:1000 at the start of hypoxia and reoxygenation.
For the normal control group and model control group, equivalent volumes of DMSO were added.

2.7. $L D H$ Release. The hypoxia and reoxygenation supernatants were collected. After $2 \mathrm{~h}$ reoxygenation, cells were lysed by freeze thawing in distilled water. LDH activities were measured using the enzymatic reaction kinetics monitoring method according to the manufacturer's instructions.

The total LDH activity was obtained from adding LDH activities in the hypoxia and reoxygenation supernatants and the cell lysate together. The LDH release rate was calculated by dividing the sum of $\mathrm{LDH}$ activities in the hypoxia and reoxygenation supernatants into the total LDH activity.

2.8. Flow Cytometry Analysis. Apoptosis was assessed by FITC-annexin V/propidium iodide apoptosis detection kit according to the manufacturer's protocol. Briefly, at the end of $6 \mathrm{~h}$ reoxygenation, cells were harvested with trypsin $(0.25 \%)$ and centrifugation (1000 rpm for $5 \mathrm{~min}$ ). Cells were washed twice with cold PBS and then resuspended in $200 \mu \mathrm{L}$ binding buffer at a concentration of $1 \times 10^{5}$ cells $/ \mathrm{mL}$. Cells were incubated with $5 \mu \mathrm{L}$ FITC-annexin $\mathrm{V}$ and $5 \mu \mathrm{L}$ propidium iodide (PI) for $15 \mathrm{~min}$ in the dark at room temperature $\left(25^{\circ} \mathrm{C}\right)$. Samples were analyzed by flow cytometry (Epics Elite, Beckman Coulter) immediately. Approximately 10000 cells were counted for each sample and data were analyzed by using Expo32 software.

2.9. Western Blot Analysis. The expression levels of cleaved caspase-3, Akt, and p-Akt were measured by western blotting. Cells were washed with prewarmed PBS and then lysed at $4^{\circ} \mathrm{C}$ with ice-cold RIPA lysis buffer (50 mM Tris ( $\mathrm{pH} 7.4$ ), $150 \mathrm{mM} \mathrm{NaCl}, 1 \%$ Triton X-100, $1 \%$ sodium deoxycholate, $0.1 \%$ SDS, $1 \mathrm{mM}$ PMSF, and phosphatase inhibitors mixture (\#P1260, Applygen Technologies Inc.)) for $30 \mathrm{~min}$. Cell lysates were then centrifuged at $12000 \mathrm{~g}$ at $4^{\circ} \mathrm{C}$ for $5 \mathrm{~min}$ and protein concentrations in the supernatants were determined by BCA protein assay kit (Beyotime Biotechnology).

Samples with equivalent amounts of total protein $(20 \mu \mathrm{g})$ were loaded and separated by $10 \%$ SDS-polyacrylamide gel electrophoresis and transferred to polyvinylidene difluoride (PVDF) membranes (Bio-Rad). The membranes were blocked in 5\% BSA for $1 \mathrm{~h}$ and then incubated overnight at $4^{\circ} \mathrm{C}$ with primary antibody (rabbit anti-cleaved caspase 3 , rabbit anti-Akt, and rabbit anti-p-Akt at 1:500, $1: 1000$, and $1: 2000$ dilution, and mouse anti- $\alpha$-actin (Beijing Biosynthesis Biotechnology, China) at 1:2000 dilution). The membranes were washed six times in $1 \times$ Tris-buffer saline-Tween 20 (TBST) buffer and then incubated with horseradishperoxidase-(HRP-) conjugated goat anti-rabbit or mouse secondary antibodies (1:40000 dilution) for $1 \mathrm{~h}$ at room temperature. After excess antibodies were removed by washing, bands were detected with an enhanced chemiluminescence (ECL) system (Thermo, USA) and visualized with the Chemi Doc XRS+ gel documentation system (Bio-Rad, USA) and analyzed by using Image lab 3.0 software (Bio-Rad, USA). The expression levels of $\alpha$-actin served as an internal control for protein loading. 


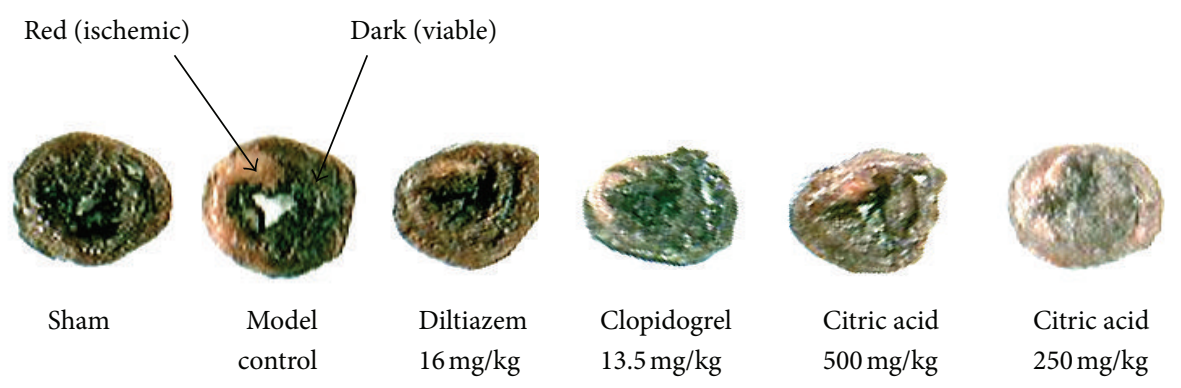

(a)

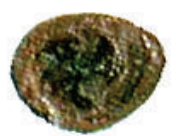

Sham

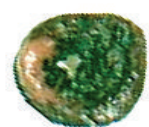

Model

control

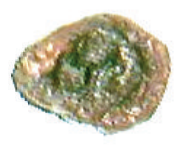

Diltiazem

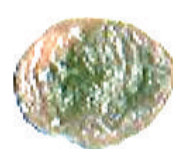

Clopidogrel $13.5 \mathrm{mg} / \mathrm{kg}$

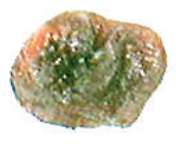

L-malic acid $500 \mathrm{mg} / \mathrm{kg}$

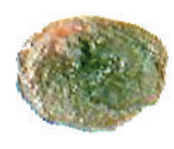

L-malic acid $250 \mathrm{mg} / \mathrm{kg}$

(b)

FIgURE 1: A representative N-BT staining of infarct size. The normal myocardium was stained dark, and the ischemic area was stained red. (a) Citric acid; (b) L-malic acid.

TABLE 1: The effect of citric acid on myocardial ischemia/reperfusion injury in rats $(\bar{x} \pm s, n=10)$.

\begin{tabular}{lccccc}
\hline Groups & Dosage $(\mathrm{mg} / \mathrm{kg})$ & Infarction of the ventricle (\%) & Infarction of the heart (\%) & Infarction area $\left(\mathrm{mm}^{2}\right)$ & Infarction weight $(\mathrm{g})$ \\
\hline Sham & - & $0.00 \pm 0.00$ & $0.00 \pm 0.00$ & $0.00 \pm 0.00$ & $0.000 \pm 0.000$ \\
Model control & - & $17.30 \pm 3.58^{\# \#}$ & $11.98 \pm 2.20^{\# \#}$ & $49.75 \pm 9.14^{\# \#}$ & $0.086 \pm 0.017^{\# \#}$ \\
Diltiazem & 16 & $8.23 \pm 2.50^{* *}$ & $5.33 \pm 1.11^{* *}$ & $21.90 \pm 4.78^{* *}$ & $0.038 \pm 0.007^{* *}$ \\
Clopidogrel & 13.5 & $11.35 \pm 2.71^{* *}$ & $8.52 \pm 1.77^{* *}$ & $35.17 \pm 9.74^{* *}$ & $0.064 \pm 0.015^{*}$ \\
Citric acid & 500 & $12.16 \pm 4.27^{* *}$ & $8.80 \pm 3.41^{* *}$ & $36.18 \pm 15.23^{* *}$ & $0.064 \pm 0.026^{*}$ \\
& 250 & $11.80 \pm 3.67^{* *}$ & $8.83 \pm 3.09^{* *}$ & $33.97 \pm 10.99^{* *}$ & $0.063 \pm 0.022^{* *}$ \\
\hline
\end{tabular}

${ }^{\# \#} P<0.01$ versus sham, ${ }^{* *} P<0.01,{ }^{*} P<0.05$ versus model control.

2.10. Statistical Analysis. All data were presented as the mean \pm SD. The data analyses were performed using one-way ANOVA analysis followed by Student-Newman-Keuls test for multiple comparisons. In all cases, values of $P<0.05$ were considered statistically significant.

\section{Results}

3.1. Effects of Citric Acid and L-Malic Acid on Myocardial Infarct Size. As illustrated in Figure 1(a) and Table 1, no myocardial infarction was observed in the sham group, while myocardial ischemia/reperfusion resulted in significant myocardial infarcts $(P<0.01)$. Diltiazem and clopidogrel, which were used as positive controls, significantly reduced infarction percentage of the ventricle, infarction percentage of the heart, infarction area, and infarction weight, as compared with the model control $(P<0.01$ or $P<0.05)$. Compared with the model control group, treatments with citric acid at the doses of $500 \mathrm{mg} / \mathrm{kg}$ and $250 \mathrm{mg} / \mathrm{kg}$ significantly reduced infarction percentage of the ventricle, infarction percentage of the heart, infarction area, and infarction weight $(P<0.01$ or $P<0.05)$.

A similar result was shown in Figure 1(b) and Table 2. Myocardial ischemia/reperfusion resulted in substantial myocardial infarcts, which were significantly reduced by treatments with diltiazem and clopidogrel $(P<0.01$ or $P<$ 0.05). Compared with the model control group, treatment with L-malic acid at the dose of $250 \mathrm{mg} / \mathrm{kg}$ significantly decreased infarction percentage of the ventricle, infarction percentage of the heart, infarction area, and infarction weight $(P<0.01)$, and treatment with L-malic acid at the dose of $500 \mathrm{mg} / \mathrm{kg}$ significantly decreased infarction percentage of the ventricle and infarction area $(P<0.01$ and $P<0.05$, resp.) but had only a tendency to reduce infarction percentage of the heart and infarction weight $(P=0.056$ and $P=0.095$, resp.).

\subsection{Effects of Citric Acid and L-Malic Acid on TNF- $\alpha$ Produc-} tion following Myocardial Ischemia/Reperfusion. Figure 2(a) showed that myocardial ischemia/reperfusion injury significantly increased the level of serum TNF- $\alpha$ compared with the sham group $(26.71 \pm 6.44$ versus $11.84 \pm 1.67 \mathrm{pg} / \mathrm{mL}, P<$ 0.05). Compared with the model control group, pretreatment with clopidogrel significantly reduced serum TNF- $\alpha$ level by $45.7 \%(14.51 \pm 3.02 \mathrm{pg} / \mathrm{mL}, P<0.01)$, and pretreatments with citric acid at the doses of $500 \mathrm{mg} / \mathrm{kg}$ and $250 \mathrm{mg} / \mathrm{kg}$ significantly reduced serum TNF- $\alpha$ levels by $15.2 \%(22.66 \pm$ 
TABLE 2: The effect of L-malic acid on myocardial ischemia/reperfusion injury in rats $(\bar{x} \pm s, n=10)$.

\begin{tabular}{lccccc}
\hline Groups & Dosage $(\mathrm{mg} / \mathrm{kg})$ & Infarction of the ventricle (\%) & Infarction of the heart (\%) & Infarction area $\left(\mathrm{mm}^{2}\right)$ & Infarction weight $(\mathrm{g})$ \\
\hline Sham & - & $0.00 \pm 0.00$ & $0.00 \pm 0.00$ & $0.00 \pm 0.00$ & $0.000 \pm 0.000$ \\
Model control & - & $9.03 \pm 3.32^{\# \#}$ & $6.00 \pm 1.67^{\# \#}$ & $32.01 \pm 11.84^{\# \#}$ & $0.051 \pm 0.014^{\# \#}$ \\
Diltiazem & 16 & $6.86 \pm 1.76^{* *}$ & $4.68 \pm 1.39^{*}$ & $25.11 \pm 6.48^{*}$ & $0.041 \pm 0.012^{*}$ \\
Clopidogrel & 13.5 & $6.51 \pm 1.58^{* *}$ & $4.75 \pm 1.19^{*}$ & $23.67 \pm 5.46^{*}$ & $0.038 \pm 0.010^{*}$ \\
L-malic acid & 500 & $6.71 \pm 1.23^{* *}$ & $4.98 \pm 0.92$ & $25.37 \pm 4.55^{*}$ & $0.043 \pm 0.009$ \\
& 250 & $6.22 \pm 1.15^{* *}$ & $4.48 \pm 0.93^{* *}$ & $22.70 \pm 4.26^{* *}$ & $0.036 \pm 0.007^{* *}$ \\
\hline
\end{tabular}

${ }^{\# \#} P<0.01$ versus sham, ${ }^{* *} P<0.01,{ }^{*} P<0.05$ versus model control.

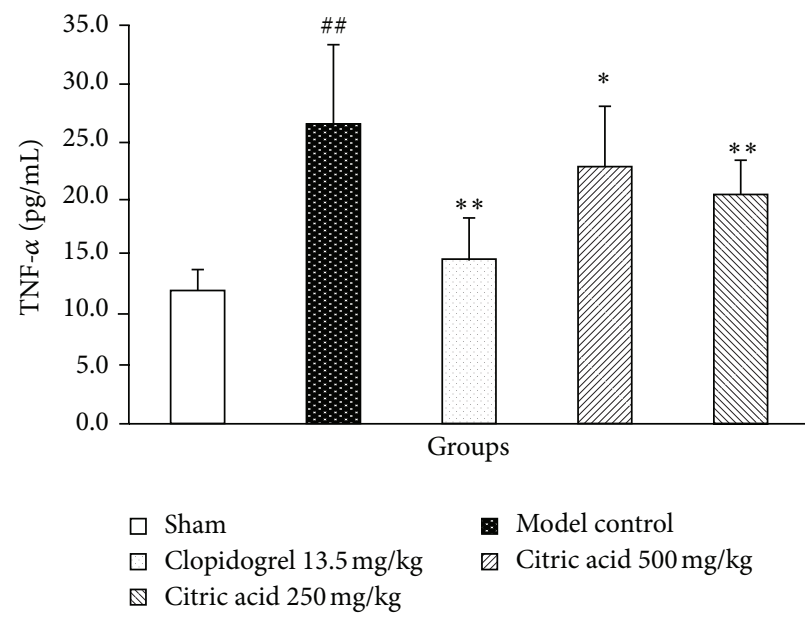

(a)

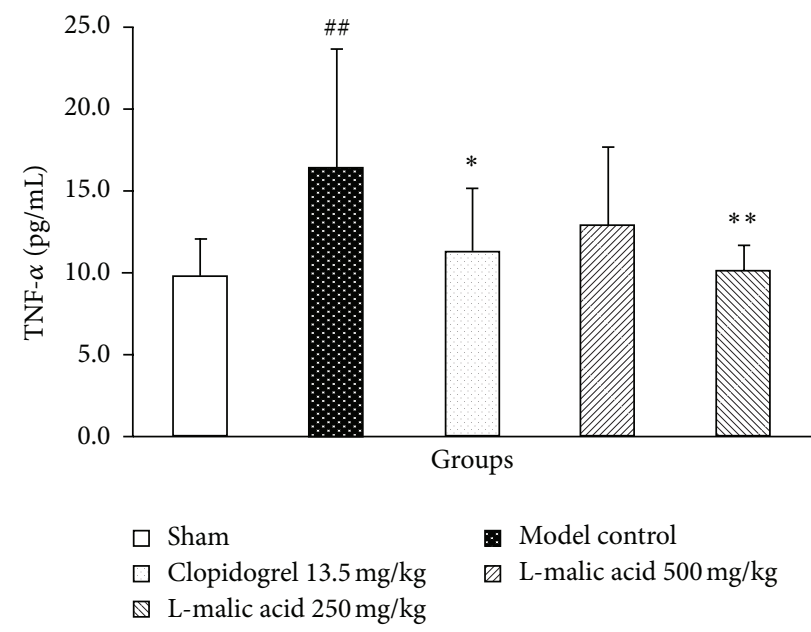

(b)

Figure 2: Effects of citric acid (a) and L-malic acid (b) on serum levels of TNF- $\alpha$ following myocardial ischemia/reperfusion. Data are shown as mean $\pm \mathrm{SD} .{ }^{\# \#} P<0.01$ versus sham, ${ }^{* *} P<0.01,{ }^{*} P<0.05$ versus model control $(n=10)$.

$5.22 \mathrm{pg} / \mathrm{mL}, P<0.05)$ and $23.3 \%(20.49 \pm 2.71 \mathrm{pg} / \mathrm{mL}, P<$ $0.01)$, respectively.

Similarly, Figure 2(b) showed that the level of serum TNF$\alpha$ in the model control group was significantly increased $(16.42 \pm 7.27$ versus $9.85 \pm 2.25 \mathrm{pg} / \mathrm{mL}$ in the sham group, $P<0.05)$. Compared with the model control group, pretreatment with clopidogrel reduced serum TNF- $\alpha$ level by $30.8 \%(11.36 \pm 3.73 \mathrm{pg} / \mathrm{mL}, P<0.05)$, and pretreatment with $\mathrm{L}$-malic acid at the dose of $500 \mathrm{mg} / \mathrm{kg}$ had only a tendency to decrease serum TNF- $\alpha$ level $(12.98 \pm 4.63 \mathrm{pg} / \mathrm{mL}, P=$ $0.129)$, while pretreatment with L-malic acid at the dose of $250 \mathrm{mg} / \mathrm{kg}$ significantly reduced serum TNF- $\alpha$ level by $37.9 \%$ $(10.20 \pm 1.50 \mathrm{pg} / \mathrm{mL}, P<0.01)$.

3.3. Effects of Citric Acid and L-Malic Acid on Platelet Aggregation Induced by ADP following Myocardial Ischemia/Reperfusion. We measured the effects of citric acid and L-malic acid on platelet aggregation induced by one of the classical endogenous agonists ADP. As shown in Figure 3(a), compared with the sham group, myocardial ischemia/reperfusion significantly increased platelet aggregation rate induced by ADP (57.53 $\pm 7.47 \%$ versus $46.81 \pm 6.18 \%, P<0.05)$. Compared with the model control group, pretreatment with clopidogrel significantly reduced platelet aggregation rate $(2.12 \pm 3.44 \%, P<0.01)$, and pretreatments with citric acid at the doses of $500 \mathrm{mg} / \mathrm{kg}$ and $250 \mathrm{mg} / \mathrm{kg}$ significantly decreased platelet aggregation rate $(35.19 \pm 13.29 \%$ and $27.50 \pm 14.08 \%$, resp., $P<0.01$ each).

A similar result was shown in Figure 3(b), the platelet aggregation rate in the model control group was significantly increased $(66.43 \pm 8.66 \%$ versus $53.06 \pm 5.27 \%$ in the sham group, $P<0.05)$. Compared with the model control group, the platelet aggregation rate for the clopidogrel group was $3.36 \pm 4.15 \%(P<0.01)$, and that for L-malic acid at the doses of $500 \mathrm{mg} / \mathrm{kg}$ and $250 \mathrm{mg} / \mathrm{kg}$ groups was $47.02 \pm 17.09 \%$ $(P<0.01)$ and $57.58 \pm 8.09 \%(P=0.149)$, respectively.

\subsection{Effects of Citric Acid and L-Malic Acid on H/R-Induced} Cardiomyocyte Necrosis. LDH leakage from cells was widely used as a reliable marker of cellular injury. The degree of $\mathrm{LDH}$ release was closely related to cardiomyocyte necrosis $[16,17]$. Thus, we explored the protective effects of citric acid and L-malic acid on H/R-induced cardiomyocyte injury in vitro by detecting LDH release. Figure 4(a) showed that after cardiomyocytes were subjected to $3 \mathrm{~h}$ hypoxia followed by $2 \mathrm{~h}$ reoxygenation, a significant $\mathrm{LDH}$ release was induced $(40.76 \pm 2.88 \%$ versus $14.57 \pm 0.96 \%$ in the normal control group, $P<0.01$ ), which were significantly inhibited by diltiazem $(23.25 \pm 2.61 \%, P<0.01)$ and citric acid at the concentration of $200 \mu \mathrm{g} / \mathrm{mL}(31.07 \pm 5.54 \%, P<0.01)$.

A similar result was shown in Figure 4(b), the LDH release rate in the model control group was significantly 


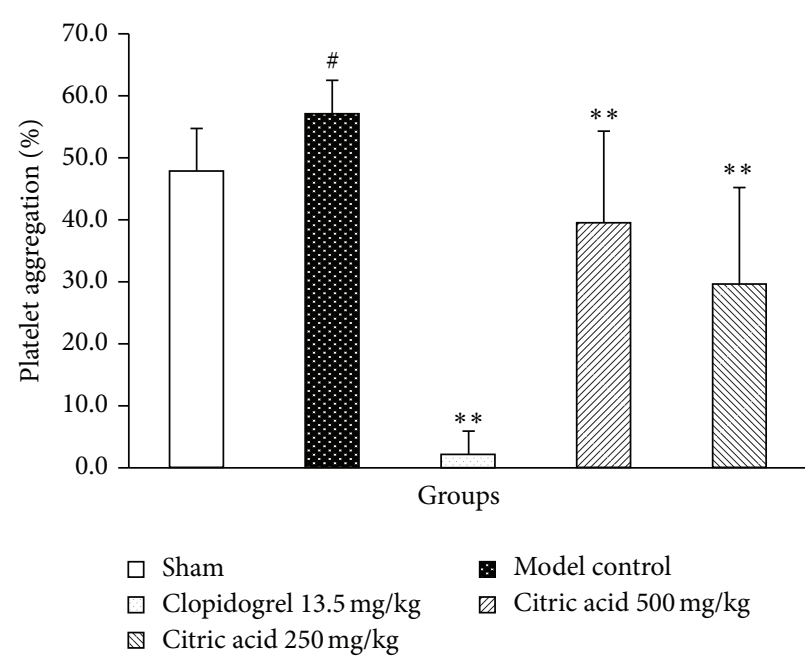

(a)

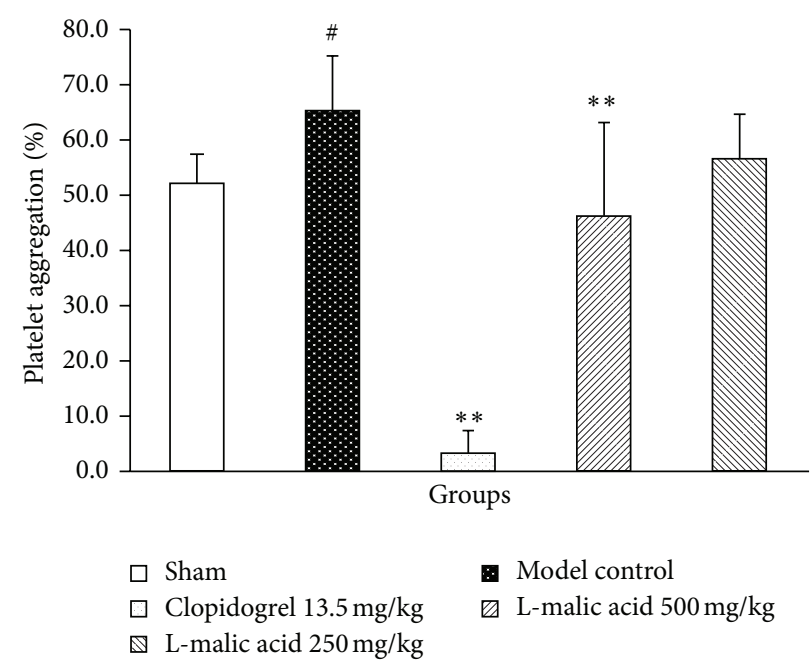

(b)

FIGURE 3: Effects of citric acid (a) and L-malic acid (b) on platelet aggregation induced by ADP following myocardial ischemi-reperfusion. Data are shown as mean $\pm \mathrm{SD} .{ }^{\#} P<0.05$ versus sham, ${ }^{* *} P<0.01$ versus model control $(n=10)$.

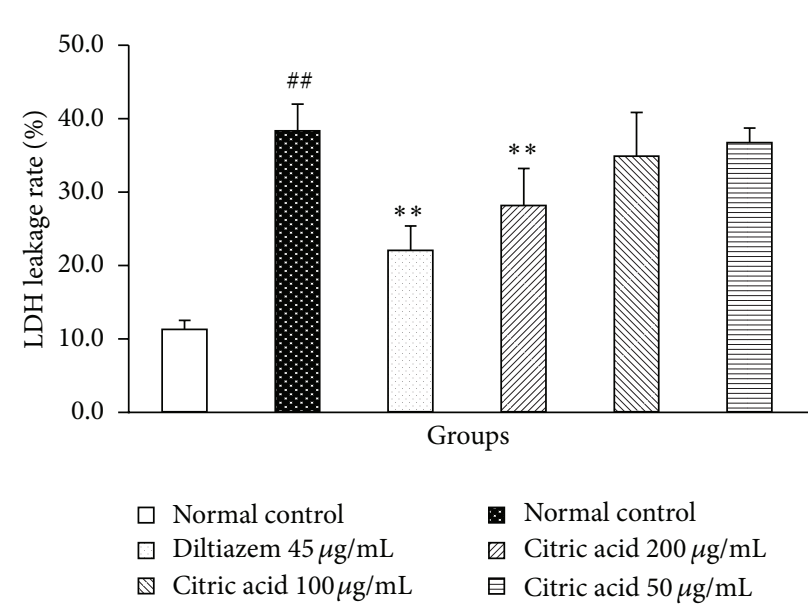

(a)

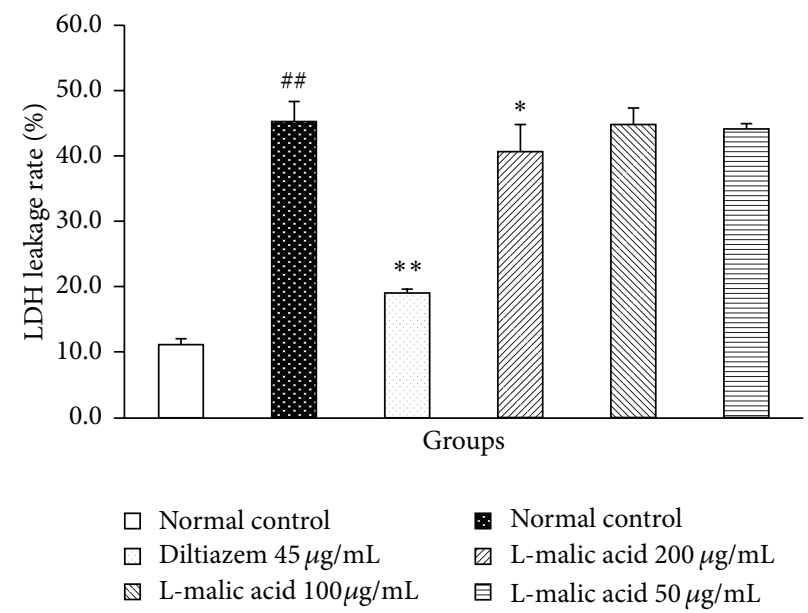

(b)

Figure 4: Effects of citric acid (a) and L-malic acid (b) on LDH release. Cardiomyocytes were subjected to $3 \mathrm{~h}$ hypoxia followed by $2 \mathrm{~h}$ reoxygenation with or without treatment. $\mathrm{LDH}$ activities in the hypoxia and the reoxygenation media and in the cell lysates were measured. Data are shown as mean \pm SD. ${ }^{\#} P<0.01$ versus normal control, ${ }^{* *} P<0.01,{ }^{*} P<0.05$ versus model control $(n=3)$.

increased $(45.31 \pm 3.00 \%$ versus $11.23 \pm 0.86 \%$ in normal control group, $P<0.01)$. Compared with the model control group, the $\mathrm{LDH}$ release rate for diltiazem group was $19.12 \pm 0.57 \%(P<0.01)$, and that for L-malic acid at the concentration of $200 \mu \mathrm{g} / \mathrm{mL}$ group was $40.69 \pm 4.03 \%(P<$ $0.05)$.

\subsection{Effects of Citric Acid and L-Malic Acid on H/R-Induced} Cardiomyocyte Apoptosis. Based on the previous results that treatments with citric acid and L-malic acid below concentration of $200 \mu \mathrm{g} / \mathrm{mL}$ could not decrease LDH release, we chose to use citric acid and L-malic acid at concentrations of $400 \mu \mathrm{g} / \mathrm{mL}$ and $200 \mu \mathrm{g} / \mathrm{mL}$ to observe whether citric acid and L-malic acid could decrease H/R-induced cardiomyocyte apoptosis. As data shown in Figure 5(a), after cardiomyocytes were subjected to $3 \mathrm{~h}$ hypoxia followed by $6 \mathrm{~h}$ reoxygenation injury, the number of apoptotic cells was significantly increased as compared with the normal control group $(25.45 \pm 1.81 \%$ versus $11.48 \pm 2.74 \%, P<0.01)$. In contrast, treatments with citric acid at concentrations of $400 \mu \mathrm{g} / \mathrm{mL}$ and $200 \mu \mathrm{g} / \mathrm{mL}$ reduced the number of apoptotic cells to $19.43 \pm 1.69 \%(P<0.01)$ and $22.70 \pm 3.47 \%(P=$ $0.179)$, respectively.

Similarly, Figure 5(b) showed that the number of apoptotic cells in the model control group was significantly increased $(22.13 \pm 1.69 \%$ versus $15.65 \pm 1.34 \%$ in the normal control group, $P<0.01$ ), which was significantly reduced by treatments with L-malic acid at concentrations of $400 \mu \mathrm{g} / \mathrm{mL}$ $(18.63 \pm 3.17 \%, P<0.05)$ and $200 \mu \mathrm{g} / \mathrm{mL}(16.70 \pm 0.62 \%$, $P<0.01)$, respectively. 


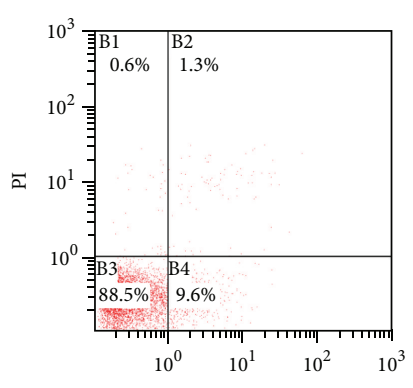

Annexin-FITC

Normal control

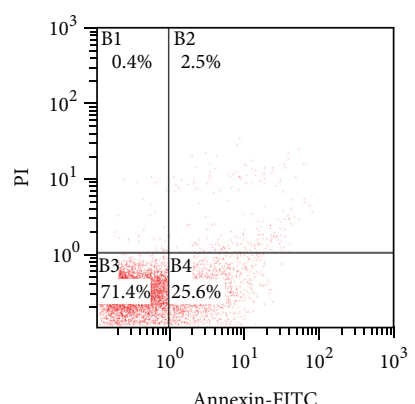

Annexin-FITC

Model control

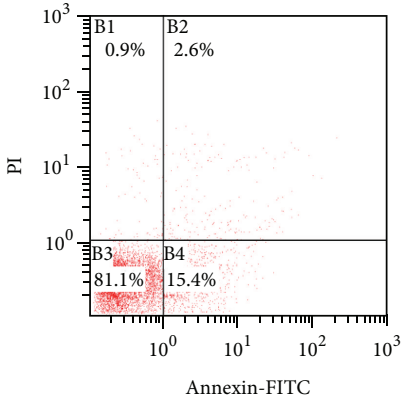

Citric acid $400 \mu \mathrm{g} / \mathrm{mL}$

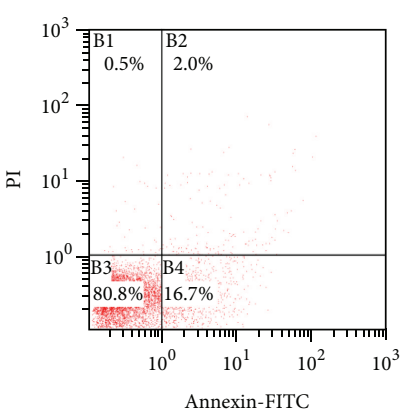

Citric acid $200 \mu \mathrm{g} / \mathrm{mL}$

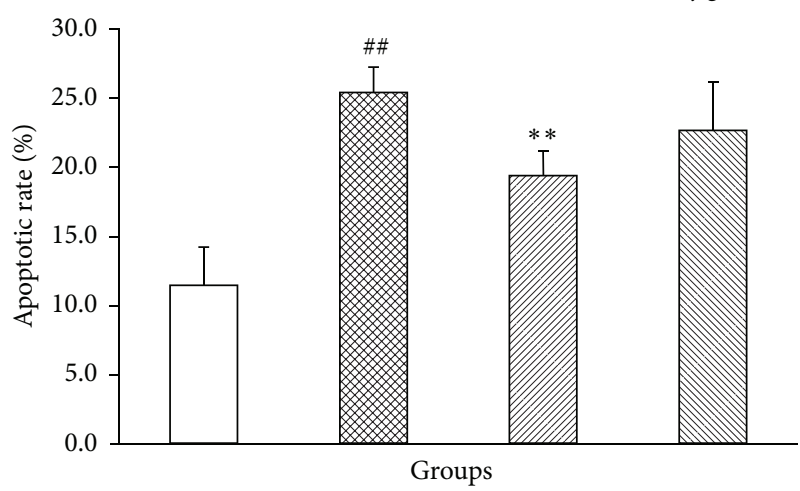

$\square$ Normal control

M Model control

Citric acid $400 \mu \mathrm{g} / \mathrm{mL}$

$\mathbb{Q}$ Citric acid $200 \mu \mathrm{g} / \mathrm{mL}$

(a)
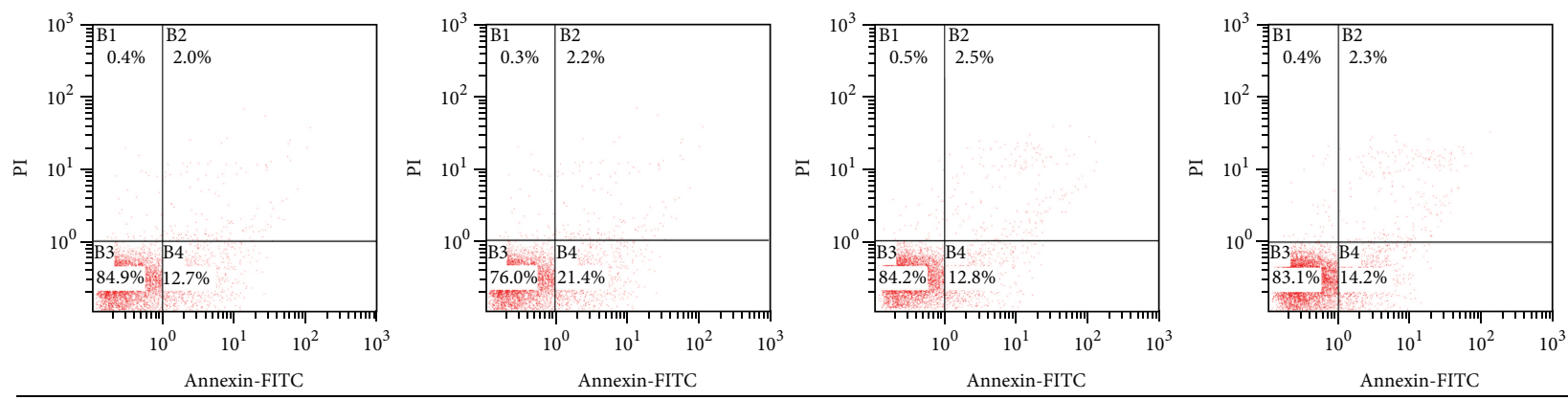

Normal control

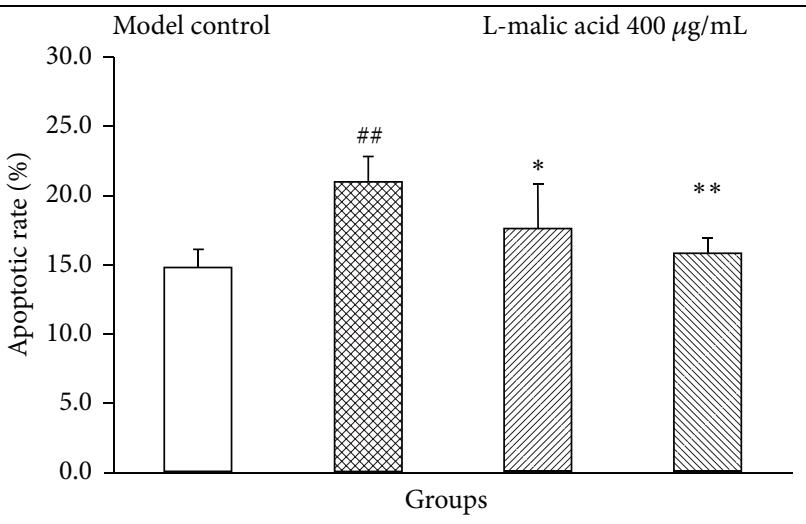

$\square$ Normal control

ه Model control

曰 L-malic acid $400 \mu \mathrm{g} / \mathrm{mL} \quad \mathbb{Q}$ L-malic acid $200 \mu \mathrm{g} / \mathrm{mL}$

(b)

FIGURE 5: Effects of citric acid (a) and L-malic acid (b) on H/R-induced cardiomyocyte apoptosis. Cardiomyocytes were subjected to $3 \mathrm{~h}$ hypoxia and $6 \mathrm{~h}$ reoxygenation in the presence or absence of citric acid or L-malic acid. Data are shown as mean \pm SD. ${ }^{\#} P<0.01$ versus normal control, ${ }^{* *} P<0.01,{ }^{*} P<0.05$ versus model control $(n=3)$. 
Normal Model L-malic acid $(\mu \mathrm{g} / \mathrm{mL})$ Citric acid $(\mu \mathrm{g} / \mathrm{mL})$ $400 \quad 200 \quad \frac{400 \quad 200}{400}$
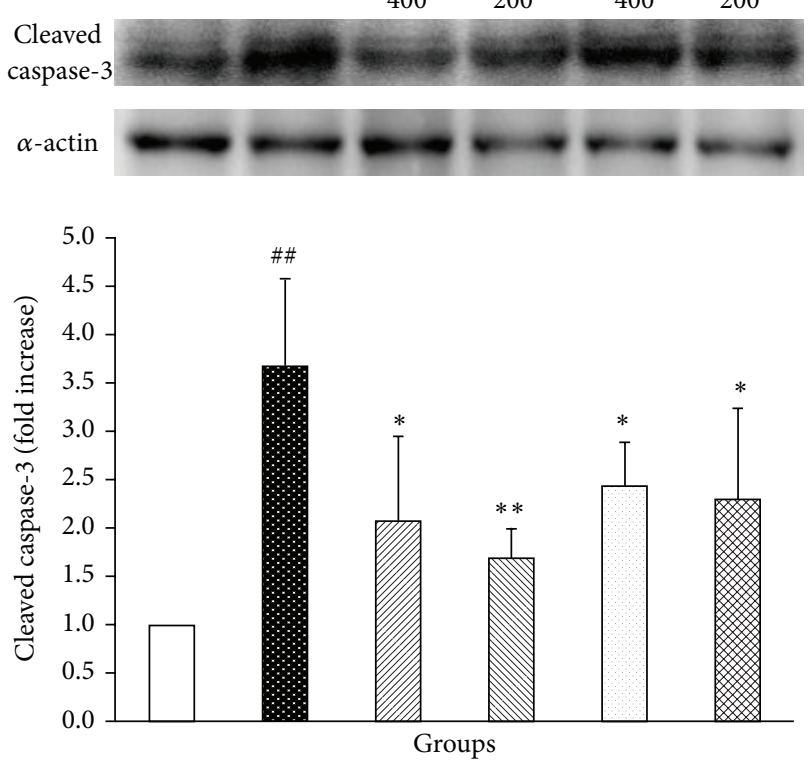

$$
\begin{aligned}
& \square \text { Normal control } \\
& \checkmark \text { L-malic acid } 400 \mu \mathrm{g} / \mathrm{mL} \\
& \square \text { Citric acid } 400 \mu \mathrm{g} / \mathrm{mL} \\
& \text { Model control } \\
& \Delta \text { L-malic acid } 200 \mu \mathrm{g} / \mathrm{mL} \\
& \text { 两 Citric acid } 200 \mu \mathrm{g} / \mathrm{mL}
\end{aligned}
$$

FIGURE 6: Effects of citric acid and L-malic acid on expression levels of cleaved caspase- 3 (fold increase relative to normal control levels) after cardiomyocytes subjected to $3 \mathrm{~h}$ hypoxia followed by $6 \mathrm{~h}$ reoxygenation. Data are shown as mean $\pm \mathrm{SD} .{ }^{\# \#} P<0.01$ versus normal control, ${ }^{* *} P<0.01,{ }^{*} P<0.05$ versus model control. Results are representative of three independent experiments.

3.6. Effects of Citric Acid and L-Malic Acid on Expression of Cleaved Caspase-3. Next we investigated the effects of citric acid and L-malic acid on expression levels of cleaved caspase3 , the activated form of caspase-3. As shown in Figure 6, western blot analysis revealed that the expression of cleaved caspase- 3 was significantly upregulated $(2.69$-fold, $P<0.01$ ) after cardiomyocytes were subjected to $3 \mathrm{~h}$ hypoxia followed by $6 \mathrm{~h}$ reoxygenation, which was significantly downregulated by treatments with citric acid at the concentrations of $400 \mu \mathrm{g} / \mathrm{mL}(33.60 \%, P<0.05)$ and $200 \mu \mathrm{g} / \mathrm{mL}(37.40 \%, P<$ $0.05)$ and treatments with L-malic acid at concentrations of $400 \mu \mathrm{g} / \mathrm{mL}(43.63 \%, P<0.05)$ and $200 \mu \mathrm{g} / \mathrm{mL}(53.93 \%, P<$ $0.01)$, respectively.

3.7. Effects of Citric Acid and L-Malic Acid on Expression Levels of Akt and p-Akt. The PI3 K/Akt pathway plays a critical role in survival after myocardial ischemia/reperfusion injury. Phosphorylation of Akt S473 represents its maximal activation $[18,19]$. To determine whether Akt was involved in citric acid and L-malic acid protection from cardiomyocyte injury, we further detected the expressions of Akt and phospho-Akt (Ser 473). As illustrated in Figure 7, western blotting results showed that total Akt was comparable in all groups. The densities of phosphorylated Akt were normalized against total Akt. We found that H/R-induced cardiomyocyte

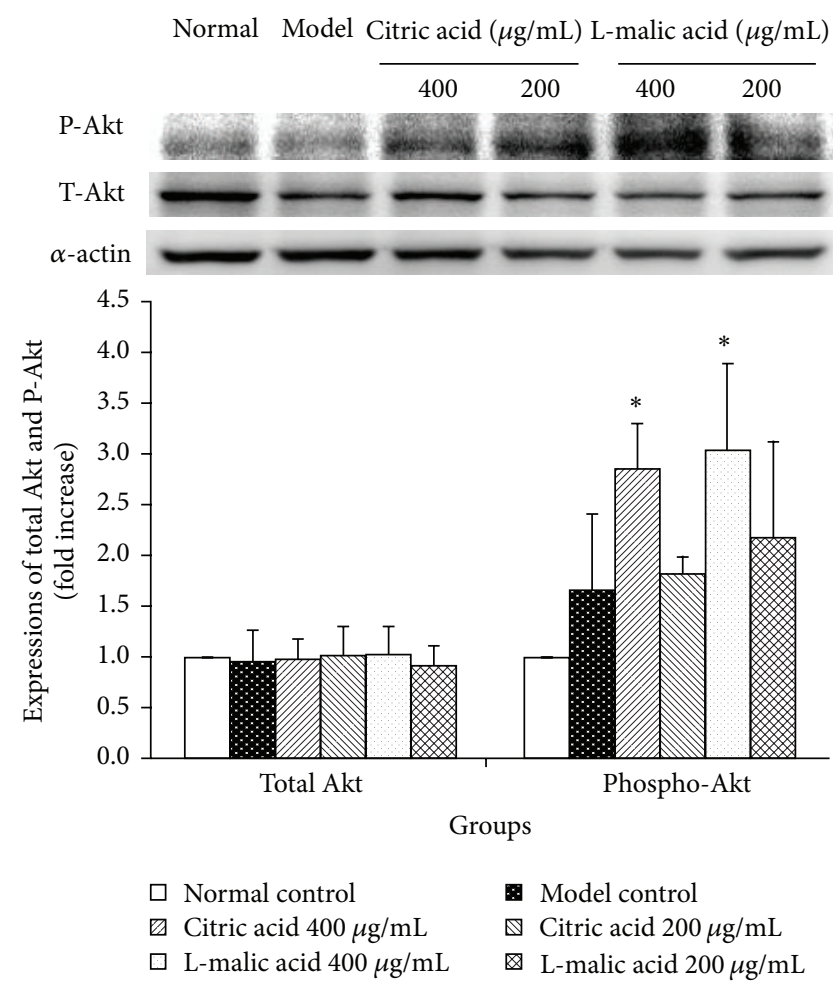

FIGURE 7: Citric acid and L-malic acid activate PI/3K and phosphorylation of Akt. A representative western blot analysis of total Akt and phosphorylation of Akt at Ser473 after cardiomyocytes were subjected to $3 \mathrm{~h}$ hypoxia followed by $6 \mathrm{~h}$ reoxygenation. Data are shown as mean $\pm \mathrm{SD} .{ }^{*} P<0.05$ versus model control. Results are representative of three independent experiments.

injury by itself resulted in a 0.67 -fold increase in Akt phosphorylation, while treatments with both citric acid at the concentration of $400 \mu \mathrm{g} / \mathrm{mL}$ and L-malic acid at the concentration of $400 \mu \mathrm{g} / \mathrm{mL}$ further significantly upregulated the expression levels of phosphorylated Akt after cardiomyocytes hypoxia/reoxygenation injury compared with the model control group (0.71-fold and 0.82-fold, resp., $P<0.05$ each). Treatments with both citric acid at the concentration of $200 \mu \mathrm{g} / \mathrm{mL}$ and L-malic acid at the concentration of $200 \mu \mathrm{g} / \mathrm{mL}$ had a tendency to increase the expression levels of phosphorylated Akt ( $9.0 \%$ and $30.54 \%$, resp., $P=0.763$ and $P=0.337$, resp.), without significant differences.

\section{Discussion}

In the present study, we reported for the first time the in vivo data demonstrating that pretreatments with both citric acid and L-malic acid significantly ameliorated the I/Rinduced cardiac injury, including reduced myocardial infarct size, decreased inflammatory cytokine TNF- $\alpha$ activity, and inhibited ADP-induced platelet aggregation. Furthermore, in vitro experiments revealed that both citric acid and Lmalic acid protected cardiomyocyte damage from necrosis and apoptosis during cardiomyocyte hypoxia/reoxygenation injury possibly via a mechanism involving PI3K/Akt survival pathway. 
In recent years, traditional Chinese medicine has been greatly developed in many countries due to its high quality and safety [20-22], and considerable attention has focused on the material basis of Chinese medicine studies. The material basis of Fructus Choerospondiatis responsible for its cardioprotective effects has been always considered to be flavonoids (mainly quercetin). However, our data in vivo demonstrated that both citric acid $(500,250 \mathrm{mg} / \mathrm{kg}$ ) and quercetin $(40,20 \mathrm{mg} / \mathrm{kg})$ significantly ameliorated the I/Rinduced cardiac injury (data unpublished), and the in vitro experiments confirmed that both organic acids (citric acid, L-malic acid, succinic acid, and tartaric acid; concentration: $400 \mu \mathrm{g} / \mathrm{mL}$ ) and flavonoids (quercetin and kaempferol; concentrations: $12.5,25,50$, and $100 \mu \mathrm{g} / \mathrm{mL}$ ) significantly decreased LDH release rate of cardiomyocytes injured by hypoxia/reoxygenation [23, 24]. Although the dosage of organic acids used in these studies was 10 30 times higher than that of flavonoids, the content of total organic acids in Fructus Choerospondiatis was nearly 30000 times higher than that of total flavonoids. Therefore, our results still furnish strong evidence that organic acids may also be the major active ingredients of Fructus Choerospondiatis responsible for its cardioprotective effects.

The extent of myocardial damage is closely related to prognosis. Therefore, determination of infarct size is the strongest determinant of prognosis of ischemic heart disease [25]. The results showed that pretreatments with both citric acid and L-malic acid significantly reduced I/R-induced myocardial infarct size and thus protected the infarcted myocardium.

Inflammatory responses and platelet aggregation have been implicated in myocardial ischemia/reperfusion injury [26]. Within minutes after reperfusion, inflammatory cascade is triggered and copious amounts of proinflammatory cytokines such as TNF- $\alpha$, IL-1 $\beta$, IL- 6 , and IL- 8 are produced and released [27]. These proinflammatory cytokines (particularly TNF- $\alpha$ ), as important factors in cardiac dysfunction, activate neutrophils and endothelial cells and aggravate myocardial ischemia/reperfusion injury [28, 29]. Platelets play a critical role in the process of myocardial ischemia/reperfusion injury. After reperfusion, platelets are immediately activated and increased, and platelet aggregability will aggravate myocardial ischemia/reperfusion injury in turn, which may be related to endothelial dysfunction and platelet-derived p-selectin, and so forth [30]. The results showed that both citric acid and L-malic acid decreased TNF- $\alpha$ level and inhibited platelet aggregation on myocardial ischemia/reperfusion injury. These data in vivo provided direct evidence that organic acids protected ischemia myocardium may be partly due to inhibition of inflammation and platelet aggregation.

Cardiomyocyte necrosis and apoptosis are the major contributors to myocardial ischemia/reperfusion injury [31]. Cardiomyocyte loss, caused by both necrosis and apoptosis, is the main feature of myocardial ischemia/reperfusion injury [32]. Necrosis and apoptosis are two distinct types of cell death with different characteristics. Necrosis leads to membrane lysis, release of cellular contents, and resulting inflammation, while apoptosis is characterized by cell shrinkage, membrane blebbing, and nuclear condensation and degradation [33]. Necrotic cells are mainly found in the central zone of the infarct, while apoptotic cells are more apparent at the marginal zone [33]. It may be beneficial for attenuating necrosis and apoptosis to prevent cardiomyocyte loss caused by myocardial ischemia/reperfusion injury. Thus, after an initial investigation of the effects of citric acid and L-malic acid on myocardial ischemia/reperfusion injury in in vivo rat model, we further observed their cardioprotective effects in cellular level. The concentrations of citric acid and L-malic acid $(400 \mu \mathrm{g} / \mathrm{mL}$ and $200 \mu \mathrm{g} / \mathrm{mL})$ used in this study had been evaluated on cytotoxicity, as determined by MTT assay. There were no significant differences between citric acid or L-malic acid at the concentrations below $500 \mu \mathrm{g} / \mathrm{mL}$ and the control group [23]. LDH is a stable cytosolic enzyme present in mammalian cells and LDH release is an indication of cell membrane integrity. The amount of LDH released from cells is proportional to the extent of membrane damage and cell necrosis [34]. The data showed that H/R injury induced significant $\mathrm{LDH}$ release, but treatments with citric acid at the concentration of $200 \mu \mathrm{g} / \mathrm{mL}$ and L-malic acid at the concentration of $200 \mu \mathrm{g} / \mathrm{mL}$ could significantly reduce cardiomyocyte $\mathrm{LDH}$ release rate.

Furthermore, we studied the effects of citric acid and Lmalic acid on hypoxia/reoxygenation-induced apoptosis by flow cytometry analysis. The results showed that H/R injury significantly increased the number of apoptotic cardiomyocytes, while treatments with citric acid at the concentration of $400 \mu \mathrm{g} / \mathrm{mL}$ or L-malic acid at the concentrations of $400 \mu \mathrm{g} / \mathrm{mL}$ and $200 \mu \mathrm{g} / \mathrm{mL}$ significantly reduced the number of apoptotic cells. The cleavage of caspase- 3 is often identified as the important step in the apoptotic signaling pathway activation process and it is considered to be a potential molecular therapeutic target for preventing cardiomyocyte apoptosis [35]. We next investigated the expression of cleaved caspase- 3 and found that the cleaved caspase- 3 was significantly upregulated by hypoxia/reoxygenation-induced cardiomyocyte injury while significantly downregulated by treatments with citric acid at the concentrations of $400 \mu \mathrm{g} / \mathrm{mL}$ and $200 \mu \mathrm{g} / \mathrm{mL}$ or L-malic acid at the concentrations of $400 \mu \mathrm{g} / \mathrm{mL}$ and $200 \mu \mathrm{g} / \mathrm{mL}$ relative to the model control group.

Akt is a potent cell survival factor and an important downstream kinase of PI3 K. The phosphorylation and activation of Akt play a pivotal role in myocardial ischemia/reperfusion injury [36]. Considerable evidence suggests that the activation of Akt reduced myocardial infarct size [17, 37]. To investigate whether Akt is involved in citric acid and L-malic acid-induced cardioprotection, we evaluated the expression of Akt and its activated, phosphorylated form (phospho-Akt) at Ser473 after hypoxia/reoxygenation-induced cardiomyocyte injury. Our results showed that treatments with citric acid and L-malic acid significantly upregulated the expression of phosphorylated Akt. All data in vitro concluded that the cardioprotection of citric acid and L-malic acid contributed to preventing cardiomyocyte from necrosis and apoptosis, which may have the PI3K/Akt survival pathway involved.

In conclusion, the present study demonstrates that citric acid and L-malic acid have protective effects on 
myocardial ischemia/reperfusion injury; the underlying mechanism may be associated with their anti-inflammatory, anti-platelet aggregation and direct cardiomyocyte protective effects. Based on these findings, we concluded that organic acids may also be the major active ingredients of Fructus Choerospondiatis responsible for its cardioprotective effects but not only flavonoids now.

\section{Conflict of Interests}

The authors declare that there is no conflict of interests.

\section{Acknowledgments}

This research was supported by grants from the National Natural Science Foundation of China (Grant nos. 81073085; 81001662) and the National Science \& Technology Major Project of China (Grant nos. 2012zx09301002-004-002; 2012zx0 9103201-049).

\section{References}

[1] A. T. Turer and J. A. Hill, "Pathogenesis of myocardial ischemiareperfusion injury and rationale for therapy," The American Journal of Cardiology, vol. 106, no. 3, pp. 360-368, 2010.

[2] National Pharmacopoeia Committee, Chinese Pharmacopoeia, vol. 1, Chemical Industry Press, Beijing, China, 2005.

[3] J. Ao, H. Feng, and F. Xia, "Transforming growth factor and nuclear factor kappa B mediated prophylactic cardioprotection by total flavonoids of fructus chorspondiatis in myocardial ischemia," Cardiovascular Drugs and Therapy, vol. 21, no. 4, pp. 235-241, 2007.

[4] G. L. Qu, "The study on pharmacodynamic material basis of Fructus Choerospondiatis and Radix et Rhizoma Rhodiolae Crenulatae," Postdoctoral Research Report, The Chinese Academy of Traditional Chinese Medicine, 2012.

[5] X. G. Liu and Y. S. Chen, "Component analysis of of fructus chorspondiatis," Chinese Wild Plant Resources, vol. 19, no. 3, pp. 35-40, 2000 (Chinese).

[6] K. K. Dharmappa, R. V. Kumar, A. Nataraju, R. Mohamed, H. V. Shivaprasad, and B. S. Vishwanath, "Anti-inflammatory activity of oleanolic acid by inhibition of secretory phospholipase $\mathrm{A}_{2}$," Planta Medica, vol. 75, no. 3, pp. 211-215, 2009.

[7] K. Takada, T. Nakane, K. Masuda, and H. Ishii, "Ursolic acid and oleanolic acid, members of pentacyclic triterpenoid acids, suppress TNF- $\alpha$-induced E-selectin expression by cultured umbilical vein endothelial cells," Phytomedicine, vol. 17, no. 14, pp. 1114-1119, 2010.

[8] K. Y. Kim, K. M. Lim, J. Y. Noh et al., "Novel antiplatelet activity of protocatechuic acid through the inhibition of high shear stress-induced platelet aggregation," Journal of Pharmacology and Experimental Therapeutics, vol. 343, no. 3, pp. 704-711, 2012.

[9] X. Wang, X. L. Ye, R. Liu et al., "Antioxidant activities of oleanolic acid in vitro: possible role of Nrf2 and MAP kinases," Chemico-Biological Interactions, vol. 184, no. 3, pp. 328-337, 2010.

[10] R. Varì, M. D’Archivio, C. Filesi et al., "Protocatechuic acid induces antioxidant/detoxifying enzyme expression through JNK-mediated Nrf2 activation in murine macrophages," Journal of Nutritional Biochemistry, vol. 22, no. 5, pp. 409-417, 2011.
[11] Z. Wang, M. Li, W. K. Wu, H. M. Tan, and D. F. Geng, "Ginsenoside Rbl preconditioning protects against myocardial infarction after regional ischemia and reperfusion by activation of phosphatidylinositol-3- kinase signal transduction," Cardiovascular Drugs and Therapy, vol. 22, no. 6, pp. 443-452, 2008.

[12] J. X. Liu, X. Z. Li, X. B. Ma et al., "Cardio-protective effects of Corocalm on acute myocardial ischemia/reperfusion injury in rats," Chinese Journal of Integrative Medicine, vol. 12, no. 3, pp. 199-202, 2006.

[13] G. V. Born and M. J. Cross, "The aggregation of blood platelets," The Journal of Physiology, vol. 168, pp. 178-195, 1963.

[14] X. O. Wang, S. Ma, and G. X. Qi, "Effect of hypoxia-inducible factor 1-alpha on hypoxia/reoxygenation-induced apoptosis in primary neonatal rat cardiomyocytes," Biochemical and Biophysical Research Communications, vol. 417, no. 4, pp. 1227-1234, 2012.

[15] P. Li, J. H. Fu, J. K. Wang, J. G. Ren, and J. X. Liu, “Extract of paris polyphylla simth protects cardiomyocytes from anoxia-reoxia injury through inhibition of calcium overload," Chinese Journal of Integrative Medicine, vol. 17, no. 4, pp. 283-289, 2011.

[16] J. Zhang, A. Liu, R. Hou et al., "Salidroside protects cardiomyocyte against hypoxia-induced death: a HIF- $1 \alpha$-activated and VEGF-mediated pathway," European Journal of Pharmacology, vol. 607, no. 1-3, pp. 6-14, 2009.

[17] H. J. Pan, D. Y. Li, F. Fang et al., "Salvianolic acid A demonstrates cardioprotective effects in rat hearts and cardiomyocytes after ischemia/reperfusion injury," Journal of Cardiovascular Pharmacology, vol. 58, no. 5, pp. 535-542, 2011.

[18] M. P. Wymann, M. Zvelebil, and M. Laffargue, "Phosphoinositide 3-kinase signalling-which way to target?" Trends in Pharmacological Sciences, vol. 24, no. 7, pp. 366-376, 2003.

[19] Y. C. Li, C. H. Yeh, M. L. Yang, and Y. H. Kuan, "Luteolin suppresses inflammatory mediator expression by blocking the $\mathrm{Akt} / \mathrm{NF} \kappa \mathrm{B}$ pathway in acute lung injury induced by lipopolysaccharide in mice," Evidence-Based Complementary and Alternative Medicine, vol. 2012, Article ID 383608, 8 pages, 2012.

[20] N. Robinson, "Integrative medicine-traditional Chinese medicine, a model?" Chinese Journal of Integrative Medicine, vol. 17, no. 1, pp. 21-25, 2011.

[21] H. Xu and K. Chen, "Complementary and alternative medicine: is it possible to be mainstream?" Chinese Journal of Integrative Medicine, vol. 18, no. 6, pp. 403-404, 2012.

[22] G. Dobos and I. Tao, "The model of western Integrative medicine: the role of Chinese medicine," Chinese Journal of Integrative Medicine, vol. 17, no. 1, pp. 11-20, 2011.

[23] X. L. Tang, J. X. Liu, L. Li et al., "Cardioprotective effects of total organic acids in Fructus Choerospondiatis on myocardial ischemia-reperfusion injury," Chinese Journal of Experimental Traditional Medical Formulae, vol. 19, no. 4, pp. 168-172, 2013 (Chinese).

[24] X. L. Tang, J. X. Liu, P. Li et al., "Protective effects of kaempferol and quercetin on hypoxia/reoxygenation and peroxidation injury in neonatal cardiomyocytes," Pharmacology and Clinics of Chinese Materia Medica, vol. 18, no. 5, pp. 243-246, 2012 (Chinese).

[25] J. Hallén, "Troponin for the estimation of infarct size: what have we learned?” Cardiology, vol. 121, no. 3, pp. 204-212, 2012.

[26] M. Akhlaghi and B. Bandy, "Mechanisms of flavonoid protection against myocardial ischemia-reperfusion injury," Journal of Molecular and Cellular Cardiology, vol. 46, no. 3, pp. 309-317, 2009. 
[27] J. Vinten-Johansen, R. Jiang, J. G. Reeves, J. Mykytenko, J. Deneve, and L. J. Jobe, "Inflammation, proinflammatory mediators and myocardial ischemia-reperfusion injury," Hematology/Oncology Clinics of North America, vol. 21, no. 1, pp. 123-145, 2007.

[28] P. Kleinbongard, G. Heusch, and R. Schulz, "TNF $\alpha$ in atherosclerosis, myocardial ischemia/reperfusion and heart failure," Pharmacology and Therapeutics, vol. 127, no. 3, pp. 295-314, 2010.

[29] N. G. Frangogiannis, C. W. Smith, and M. L. Entman, "The inflammatory response in myocardial infarction," Cardiovascular Research, vol. 53, no. 1, pp. 31-47, 2002.

[30] Y. Xu, Y. Huo, M. C. Toufektsian et al., "Activated platelets contribute importantly to myocardial reperfusion injury," American Journal of Physiology-Heart and Circulatory Physiology, vol. 290, no. 2, pp. H692-H699, 2006.

[31] M. I. Oerlemans, S. Koudstaal, S. A. Chamuleau, D. P. de Kleijn, P. A. Doevendans, and J. P. Sluijter, "Targeting cell death in the reperfused heart: pharmacological approaches for cardioprotection," International Journal of Cardiology, vol. 165, no. 3, pp. 410-422, 2013.

[32] Y. Fujio, T. Nguyen, D. Wencker, R. N. Kitsis, and K. Walsh, "Akt promotes survival of cardiomyocytes in vitro and protects against lschemia-reperfusion injury in mouse heart," Circulation, vol. 101, no. 6, pp. 660-667, 2000.

[33] A. Hamacher-Brady, N. R. Brady, and R. A. Gottlieb, "The interplay between pro-death and pro-survival signaling pathways in myocardial ischemia/reperfusion injury: apoptosis meets autophagy," Cardiovascular Drugs and Therapy, vol. 20, no. 6, pp. 445-462, 2006.

[34] L. Parhamifar, H. Andersen, S. M. Moghimi et al., "Lactate dehydrogenase assay for assessment of polycation cytotoxicity," Methods in Molecular Biology, vol. 948, pp. 13-22, 2013.

[35] S. A. Lakhani, A. Masud, K. Kuida et al., "Caspases 3 and 7: key mediators of mitochondrial events of apoptosis," Science, vol. 311, no. 5762, pp. 847-851, 2006.

[36] L. Ji, F. Fu, L. Zhang et al., "Insulin attenuates myocardial ischemia/reperfusion injury via reducing oxidative/nitrative stress," American Journal of Physiology-Endocrinology and Metabolism, vol. 298, no. 4, pp. E871-E880, 2010.

[37] T. Matsui, J. Tao, F. del Monte et al., "Akt activation preserves cardiac function and prevents injury after transient cardiac ischemia in vivo," Circulation, vol. 104, no. 3, pp. 330-335, 2001. 


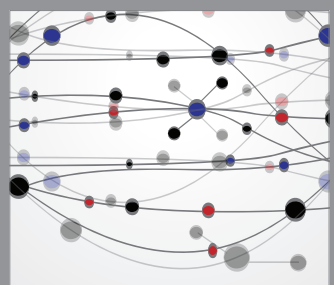

The Scientific World Journal
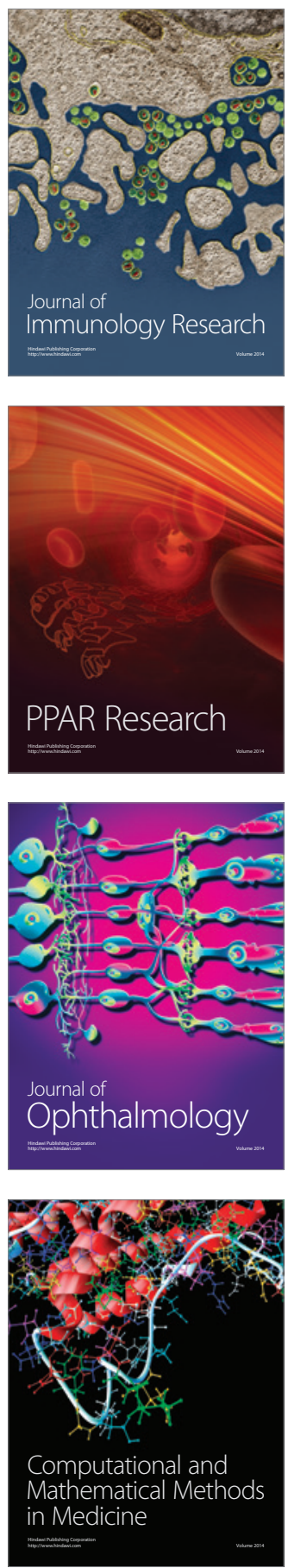

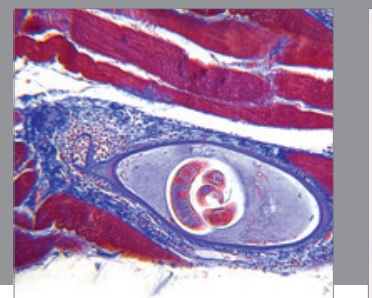

Gastroenterology

Research and Practice
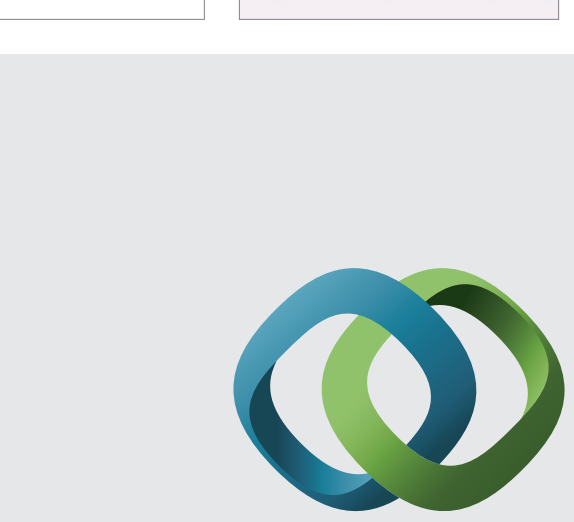

\section{Hindawi}

Submit your manuscripts at

http://www.hindawi.com
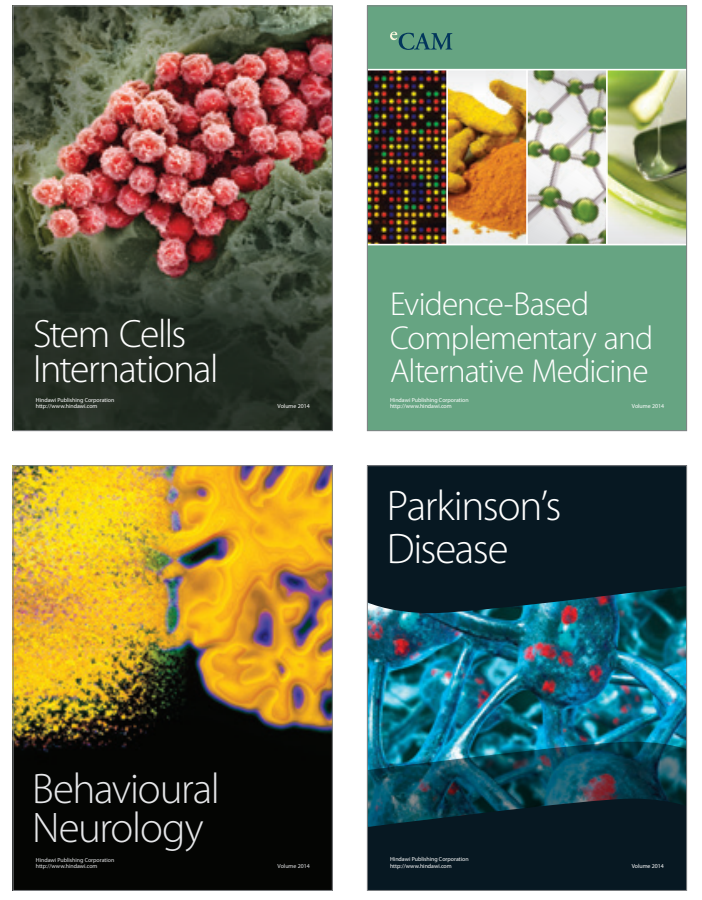
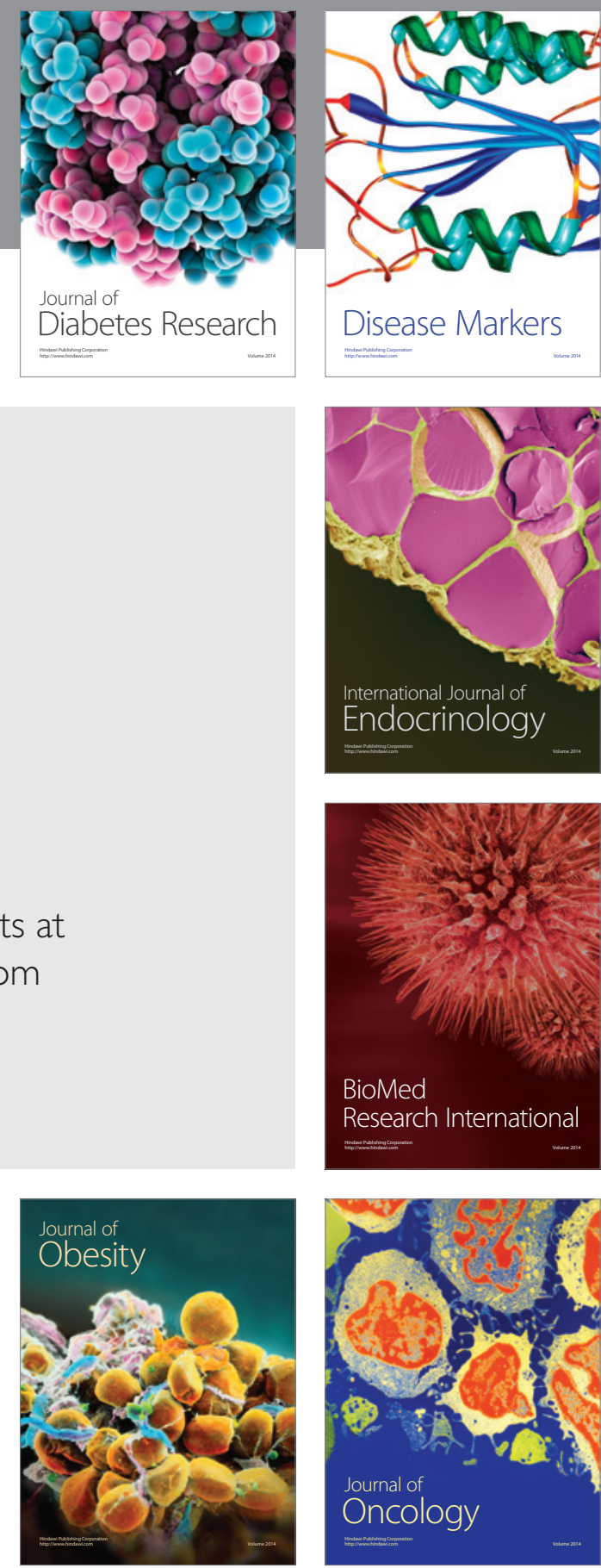

Disease Markers
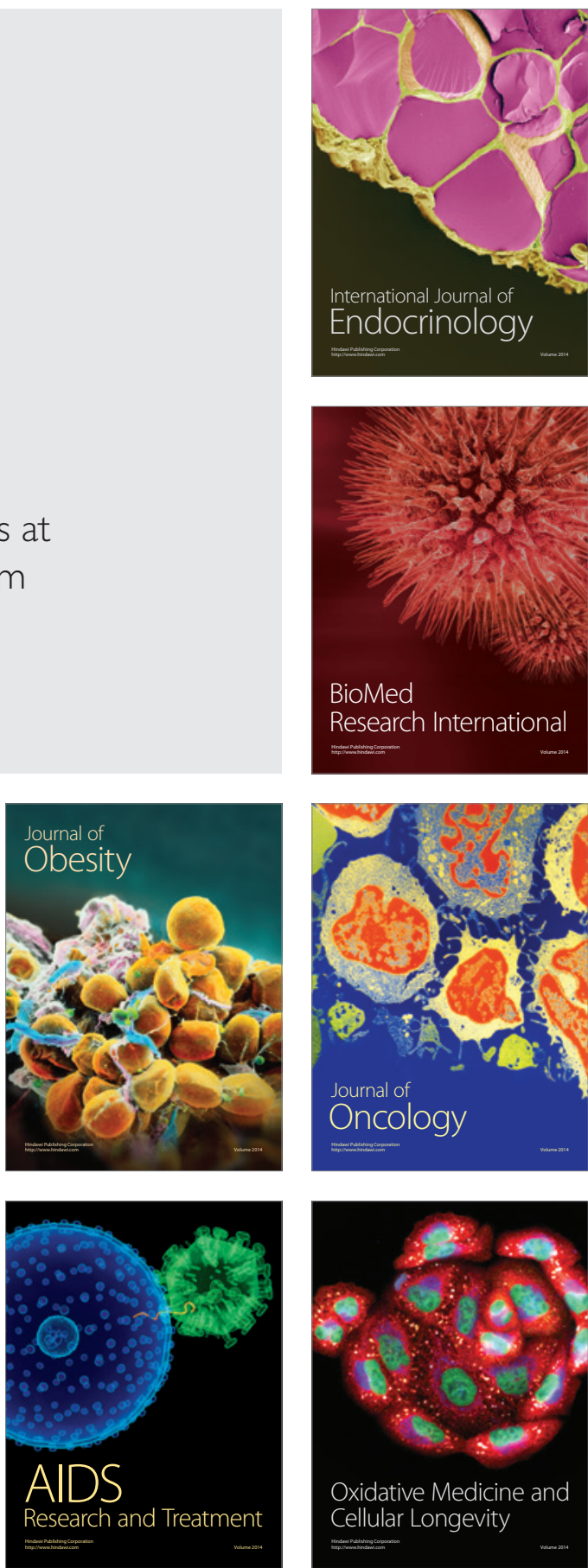